\title{
Game-Based Trust
}

\author{
Sebastian Matyas ${ }^{1,2}$, Daishi Kato ${ }^{2}$, Takao Shime ${ }^{2}$, \\ Kazuo Kunieda ${ }^{3}$, and Keiji Yamada ${ }^{2}$ \\ ${ }^{1}$ Japanese Society for the Promotion of Science Fellow \\ ${ }^{2}$ NEC C\&C Innovation Initiative, \\ ${ }^{3}$ NEC Capital Solutions Limited, \\ 8916-47, Takayama-cho, Ikoma, Nara, 630-0101, Japan \\ smatyas7@googlemail.com, \\ daishi@cb.jp.nec.com, t-shime@ce.jp.nec.com, \\ k-kunieda@ak.jp.nec.com, kg-yamada@cp.jp.nec.com
}

\begin{abstract}
Trust stands at the beginning of every meaningful interaction between members of any kind of community - be it in the real world or in a virtual one. But how could an application look like that helps to create or even foster the interpersonal trust of its users? We developed a game - Kokochi with the goal to positively affect the interpersonal trust level of its players. We evaluated Kokochi in two case studies and compared the results with a control group that didn't play the game. We could show that playing the game - featuring three unique game elements to enhance trust: disclosure of personal information (emotional statements), collaborations (face-to-face) and showing goodwill towards other players (virtual hugging) - resulted in an (significant) higher interpersonal trust level of the subjects after the game than they had before.
\end{abstract}

Keywords: Emotion, Trust, Location-based gaming, Collaboration.

\section{Introduction}

For several decades researchers have discussed about the various definitions of trust and depending on the research field (Psychology, Social Sciences, Computer Sciences - especially MAS (Multi-Agent-Systems) and virtual communities - or others) they associated various properties with the term "trust". For an overview on these properties of trust see e.g. the works of Kramer (1999), Marsh (1994) and Goldbeck (2005, 2006). Although certainly not complete the following properties are the most noted ones: Social uncertainty ${ }^{1}$, Commitment (Dellarocas, 2003) ${ }^{1}$, Goodwill/Benign intent $^{1,2}$, Reputation ${ }^{1}$, Consistency ${ }^{1}$ (Past experience/interaction), Delegation ${ }^{2}$ (Castelfranchi and Falcone, 1998), Attitude/Mood/Optimism² (Jones, 1996) and Confidence (Golembiewski and McConkie 1975).

\footnotetext{
${ }^{1}$ Yamagishi and Yamagishi (1994); Yamagishi, Cook, Watabe (1998).

2 Subsumed under the term "emotion".
} 
But how could an application look like that helps to create or even foster the interpersonal trust of its users? Which kinds of features are appropriate to help realizing one or more of the above mentioned properties of trust?
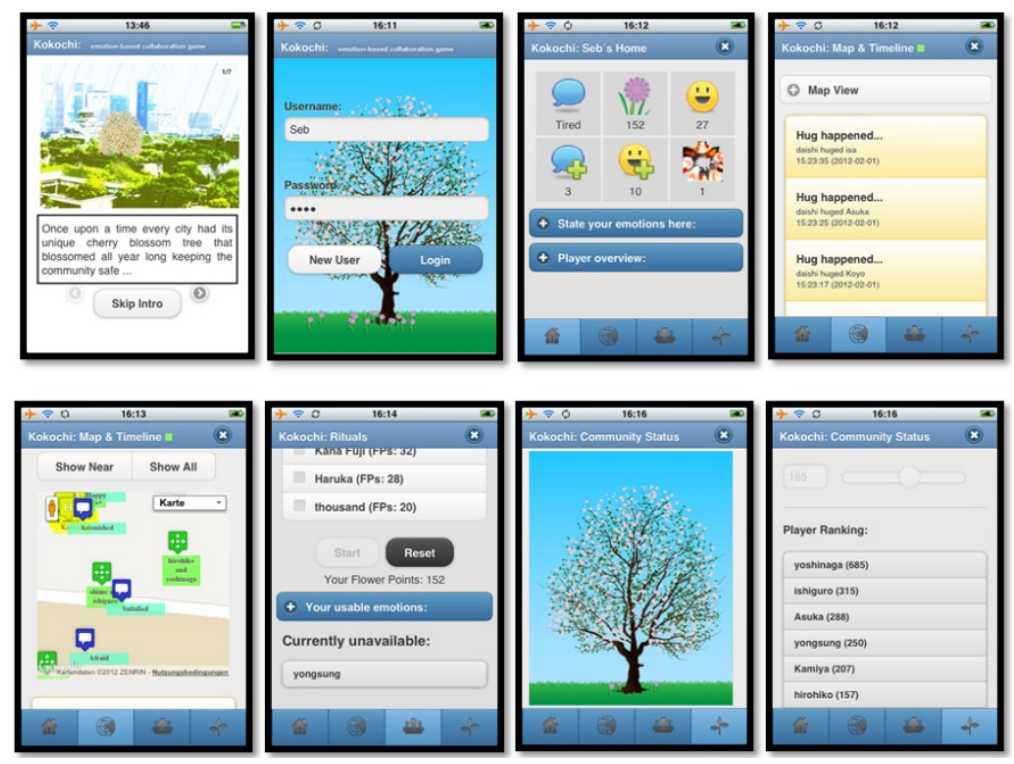

Fig. 1. (top row): Intro, Log in, Home and Timeline screen; (bottom row): Map, Ritual, Community Tree and Player ranking screen

It is a well accepted fact that games can be used to motivate people to take part in various kinds of activities they otherwise would be more reluctant to do - for example to do sport activities (Mueller et al. 2007), to look after one's health (Anderson et al. 2007), learning (Johnson 2010) or even to work for free (like labeling photos on the web or map the world, Ahn and Dabbish 2008). The first two practices are used in the research of serious gaming while the later one is featured in the human computation (Ahn and Dabbish 2008) and volunteered geographic information (VGI) (Goodchild 2007) field.

We use the motivational ability of a location-based game to foster interpersonal trust in a real-world community of players. Therefore we present the game Kokochi (Figure 1 shows screenshots of our current build) that implements unique game elements to realize three of the above mentioned properties - social uncertainty, commitment and goodwill:

- disclosure of personal information (emotion statements) - Home screen (Fig. 1)

- collaborations (face-to-face) - Ritual screen (Fig. 1)

- showing goodwill towards other players (virtual hugging) - Home screen (Fig. 1) 
Kokochi is both a collaborative and competitive game experience that significantly affects the interpersonal trust level of its players.

The rest of the paper is structured as follows: In the next section we will outline the related work with regard to trust in general and some of its properties that were already used in game-like applications. Section 3 introduces our Kokochi game and its trust fostering game elements. We evaluated our game in two case studies - described in section 4 - which results in a significant rise of the interpersonal trust level of its participants. In the last section we discuss this result and give an outlook on further studies.

\section{Related Work: Collaboration, Trust, Emotions}

According to the uncertainty reduction theory (URT) after Berger and Calabrese (1975) - see also Blanchard and Markus (2004) and Virtanen and Malinen (2008) one of the aims in every interpersonal interaction is to get to know as much personal traits of your interaction partner as possible. This personal identity disclosure leads to more trust and communication between them. As there are numerous personal traits that one can disclose to other people we were looking at those that are especially suitable for a game-based experience.

Emotions are an essential part of every game-based experience. Research topics like immersion (Carrigy 2010) and game-flow (Jegers 2007) are well established in the game research community. And everyone that has played a game with friends or strangers over the internet or in a living room can tell some funny, angry, sad or happy stories that happened while playing the game. Our idea is to let players communicate their emotions during game play as one part of their personality.

From the literature (Lount 2010) it is known that emotions, or moods (sometimes there is no clear distinction between the two), can have a significant effect on the judgments we make about other people. Two main models are extensively investigated in this context. On the one hand we have the Mood-Congruent model (Mayer et al. 1992) that simple says that your judgments are influenced in the direction of your current mood state. So if you are in a positive (negative) mood your judgment will also be more positive (negative) too. On the other hand we have the AccommodationAssimilation model (Bless and Fiedler, 2006) that makes the point that under a positive mood people are more sensible about clues that either supports a positive or negative judgment of other persons, leading to more or less trust. In either way there seems to be a positive correlation between mood and how you judge respectively trust other people. So far neither the Mood-Congruent nor the Accommodation-Assimilation model has been used in a real-world application.

The works of George and Brief (1992) and others have shown one interesting way to get people into a positive mood and that is by getting them to do some good task. They look especially into tasks for the public good where there is no monetary gain to be achieved. One prominent example is donating money to a non-profit organization or community service. In correspondence with the above mentioned mood-trust models this could lead to some promising applications as we will see in this paper. 
Bernhaupt et al. (2007) and Church, Hoggan and Oliver (2010) are two of the more recent examples that uses emotions in their research. The first one is a game-like application where the emotional states of office workers are detected via facial expression recognition. The more positive expressions of a player are recorded the faster he lets a virtual flower grow. The player who first lets his flower fully grow wins the game. The authors report that this kind of game can increase for example communication between the players.

In the later one the authors present MobiMood, an iPhone app, that lets its users share their current emotional state. To do this they simple have to select one of the predefined emotions in the app or create a new one and send it to all the other users of the app. In addition the location where the emotion was experienced is shared as well. Though the study was more focused on design principles one interesting result was that it enhanced the communication between the users also outside of the application itself. The connection to interpersonal trust was not analyzed.

Research on trust in virtual teams e.g. by Jarvenpaa and Leidner (1999) focuses more on what kind of effect trust has on the successful outcome of a project. Our focus is to identify game elements that can help to foster interpersonal trust. In the same context Lionel et al. (2009) investigate the occurrences of "swift trust" in virtual teams but don't propose any specific techniques to build up trust in such teams.

\section{Kokochi: Emotion-Based Collaboration Game}

Our game Kokochi is both a collaborative and competitive game experience. The background story tells about a cherry blossom tree that once blossomed throughout the whole year and kept the community of the players save from evil. But because the people living in the community stopped to share their emotional state with each other the tree withered and lost its protective power.
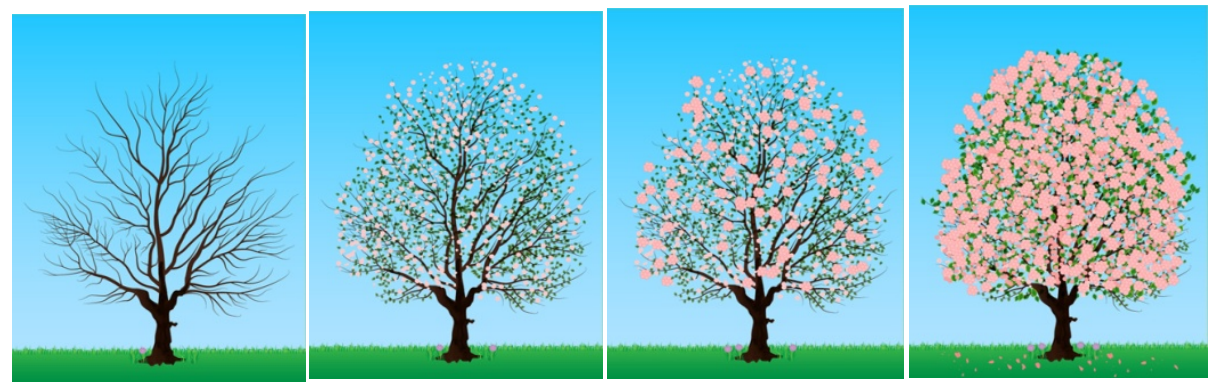

Fig. 2. The four possible states of the cherry blossom tree in Kokochi; when the last state is reached the game ends

The collaborative goal of Kokochi is now to help the communities cherry blossom tree to fully blossom again. The players can achieve this goal by successfully performing a ritual with at least one other player in the game. In order to perform a successful ritual at least one of the collaborative players has to have a specific 
combination of emotions that is unknown to them before they start a ritual. The game ends when the last of four blossom states is reached - Figure 2 shows all possible blossom states of the cherry blossom tree in the game. The number of cherry blossom states in our study has been chosen to make the game evenly paced. The one player that helps most to restore the power of the tree gains a free wish from him (see also ${ }^{3}$ for the corresponding comic strip).

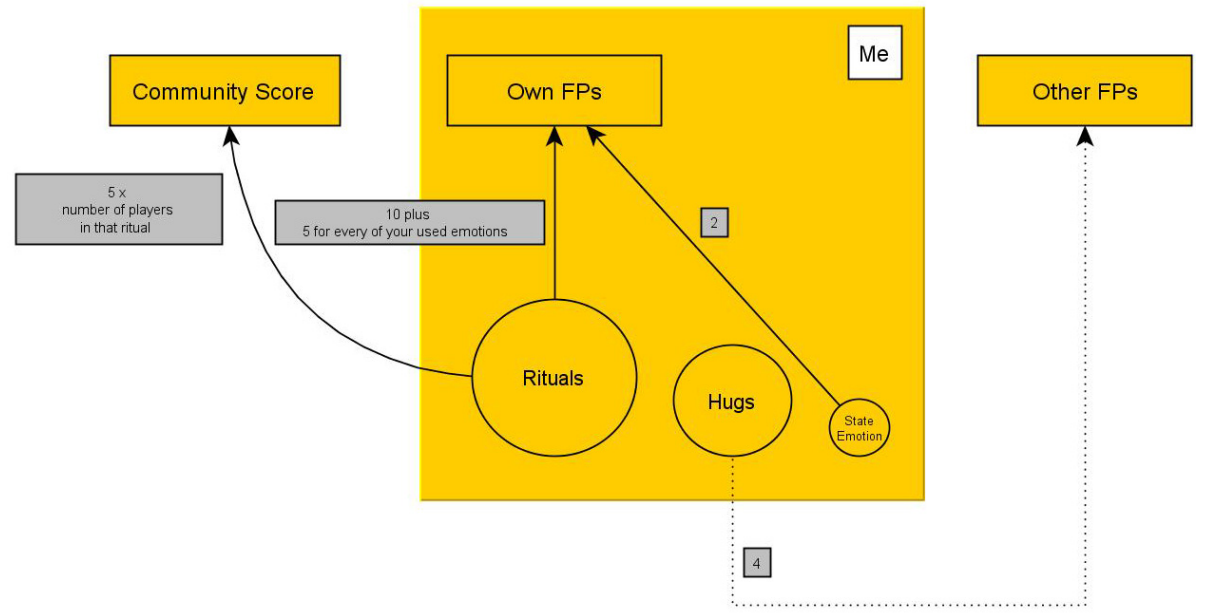

Fig. 3. Scores in Kokochi (FPs = Flower Points)

To achieve this competitive goal of Kokochi a players needs to have the most Flower Points (FPs) when the cherry blossom tree reaches its fourth blossom state. A player gains FPs by stating emotions ( 2 FPs) by getting hugged by other players (4 FPs) and by successfully performing rituals with other players $(10+5$ FPs for every emotion of a player that is used to fulfill the required emotion combination) - see Figure 3 for a structured overview of the point allocation for each game activity. The specific point counts were chosen so that a game of Kokochi would last - depending of the number collaborations between the players - on average around a week.

Consequently the game features two kinds of scores one for each goal. The community score keeps track of the progress of all players in the game - the collaborative game part - and the FPs keep track of the progress of an individual player - the competitive game part. Players have to keep both scores in mind when they play the game as they don't want to end the game by contributing to the community score before their individual score is high enough. This leads to some interesting game design decisions that we will discuss in the following when we look into the individual game elements of Kokochi.

The game itself is realized as a HTM5 web-application and therefore runs on any kind of mobile device.

\footnotetext{
${ }^{3}$ http: //81.20.134.106/ moodGame/m.kokochi.html
} 


\subsection{Stating Emotions and Virtual Hugs}

The game features 28 predefined emotions organized in four distinguish categories excited, relaxed, depressed and frustrated. All emotions are taken from Russell (1980). Players can state any emotion freely throughout the game. As emotions can change rather quickly - according to the literature they normally last no longer than 15 minutes - we made it possible that a player can state up to three emotions during a period of 20 minutes. During these 20 minutes any combination of emotion statements is possible, the player can even state three identical emotions to emphasize in some way the strength of her emotion. Figure 4 shows that stating an emotion is simple done by pressing a button.

But the 20 minute time restriction also serves as a soft cheating prevention mechanism. Because we have no way to verify if players truly state their emotion the players could just state continuously any kind of emotion and gather FPs very quickly in this way. With the time constraint a player has at least to wait the full 20 minutes until she can state three fresh emotions and there is a clear limit to the number of FPs one can achieve in this way.

Another anti-cheating measurement is the relatively low amount of FPs an emotion statements earns a player (2 FPs). He would have to state emotions for more than half an hour for example to make up for only one ritual that another player could perform in the same time frame. These measurements together with the way rituals are performed should make it very unattractive for a player to falsely state his emotions.
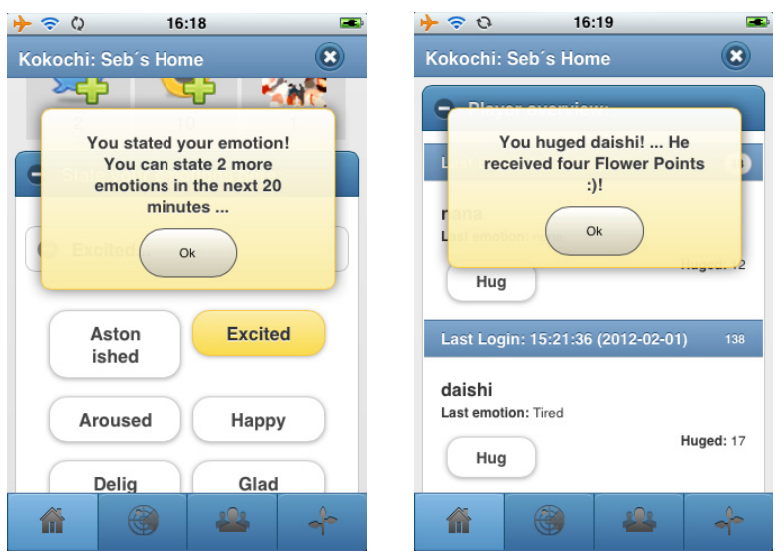

Fig. 4. Stating emotions (left) and hugging (right)

Every player can give any other player a virtual hug in the game. As stated in the introduction these virtual hugs should give the players the opportunity to show goodwill towards the other players to rise their and the other players mood within the game in the long term. Consequently hugging another player is not only a nice gesture like 
for example the like-button in Facebook $^{4}$ but also bears additional meaning: the hugged player receives four FPs for free.

Again this could be potentially be misused by pairs or groups of players who hug each other continuously during the game. That is why each player can only send ten hugs to another player during a period of 24 hours.

For both, emotion statements and hugs, the GPS coordinate was recorded. This way a player can see where each of the above described game actions took place by selecting the Map screen of Kokochi.

\subsection{Performing Rituals}

Rituals are the only way to actually finish the game. A ritual can be performed by two or more players. To perform a ritual they have to select their ritual partners on the ritual page in Kokochi and then press the start button - see Figure 5. The game internally then randomly builds an emotion pattern. If the players have stated the emotions that the game chose for the pattern any time before the collaboration they succeed in performing the ritual and get their FPs as well as let the cherry blossom tree grow through the community score. The players only know about the composition of the generated emotion pattern after the ritual is performed. If the ritual was successful the players lose the emotions used for that ritual so that they have to state that emotion again before they can use them in another ritual.
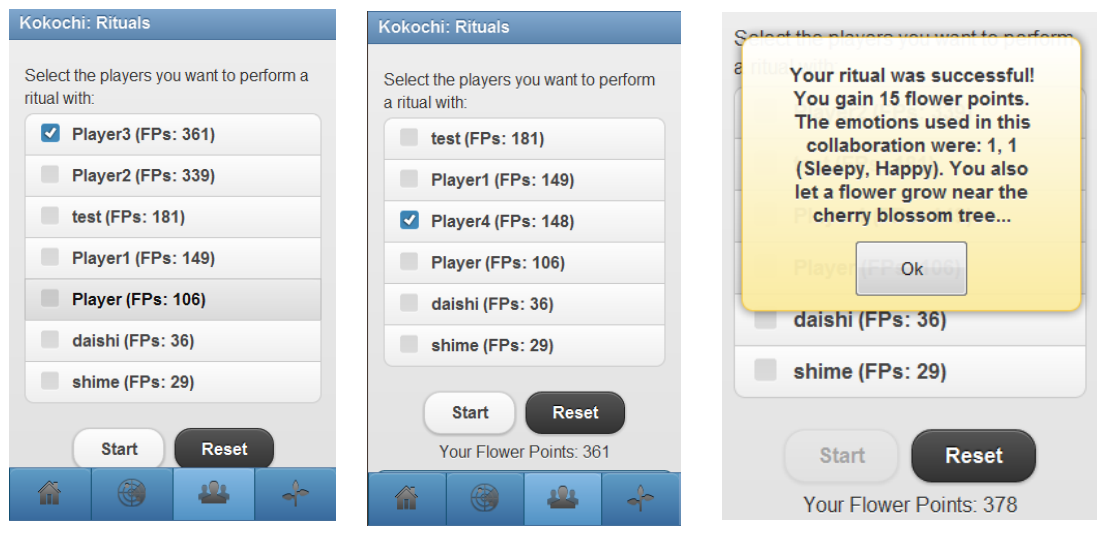

Fig. 5. (left to right): Player $4 \mathrm{~s}$ ritual screen, Player $3 \mathrm{~s}$ ritual screen, Ritual successful message

Once again cheating is the main reason to keep the pattern information hidden from the players. Our goal here was to not give the players any motivation to just state the emotions needed to successfully perform a ritual but let them state their true emotions.

The emotion pattern changes with every ritual - that is how many emotions are needed in total, the type of emotion that is needed and how many of each individual

${ }^{4}$ www. facebook. de 
emotion the players need. Figure 5 shows an example of a successful ritual. Here player 3 and 4 want to collaborate and perform a ritual together. So they meet face-toface, select one another on the list of players and then start the ritual. Note that Kokochi features no communication function like chatting or email on purpose to make the players talk to each other face-to-face to initiate the ritual in the first place. In our example the game generated the pattern (Sleepy, Happy). The $(\mathbf{1 , 1})$ shows that both emotions are only need a single time. Now one of the players needs to have stated either Sleepy or Happy or both sometime before this ritual took place in order to make in successful.

From the literature (Matyas et al., 2009, and Bell et al., 2006) we know that if players fall behind on a leader board too much they become uninterested in a game very fast. Kokochi tries to solve this problem with how the emotion pattern is generated by the game.

First of all in the early stages of the game - also depending on how many emotions the players already stated at the point in time they perform a ritual - every ritual succeeds. This is done to not let the players lose their interest early in the game. Secondly the emotion pattern is constructed by the game so that - if it is possible - more emotions of the lower ranked player are used for the pattern as from the higher ranked player in such collaboration. In this way the lower ranked player always gets more points out of a successful ritual. Therefore the lower ranked players have an incentive to perform rituals with higher ranked players and the higher ranked players need to perform rituals either way to finish the game and win.

As for emotion statements and hugs, the GPS coordinate for successful rituals are recorded and visualized on the Map screen of Kokochi.

\section{$4 \quad$ Fostering Trust with Kokochi}

To evaluate Kokochi and its trust fostering abilities we conducted two case studies in February/March of 2012. One 3-week case study with 11 members of our laboratory (the $\mathrm{CCIL}^{5}$ ) consisting of 9 male and 2 female players was carried out. Furthermore a 3 -day study took place with 6 NAIST university ${ }^{6}$ students -5 male and 1 female players. The age average for the CCIL study was 34,8 and for the NAIST study 29,5. The participants in the former study were all Japanese researchers and in the later international computer science PhD students.

At the start of each study the trust score of each participant was recorded using Rottens (1967) interpersonal trust questionnaire - reprinted in Robinson et al. (1991) It contains of 25 questions and results in a numeric trust value (ranging from 25 to 125 points). The same questionnaire was used at the end of each study to evaluate the change in the trust scores for the players. Additionally all players filled out a general game-related questionnaire after the study that we designed for these studies.

\footnotetext{
${ }^{5}$ http://www.nec.co.jp/ra/en/ccil/

${ }^{6}$ http://www.naist.jp/index_j.html
} 


\subsection{Case Study Results}

We used a One-Way ANOVA test (using $\mathrm{R}^{7}$ as our statistic software) to verify if the recorded trust levels of the participants changed significantly. See Figure 6 for the boxplot of the individual trust scores of the participants before (base) and after (post) the game for the CCIL (1) and the NAIST (2) study.

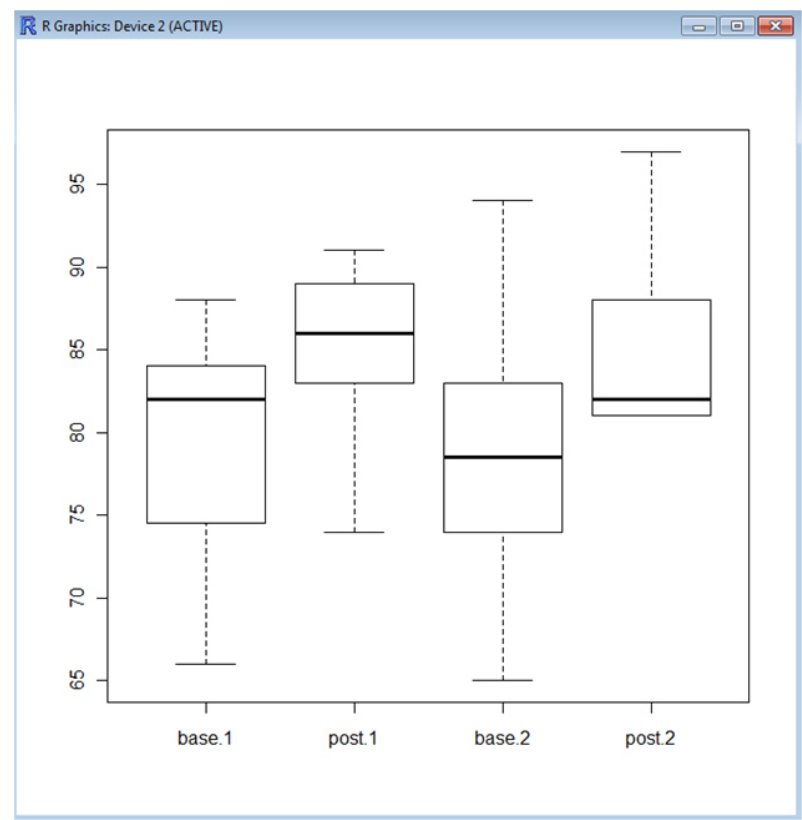

Fig. 6. Trust values before (pre) and after (post) the CCIL Kokochi (1) and the NAIST (2) game ( $n=11$ for base-Group and $n=9$ for post-Group in the CCIL study and $n=6$ for base/postGroup)

Table 1. ANOVA result of CCIL game (left) and the NAIST game (right)

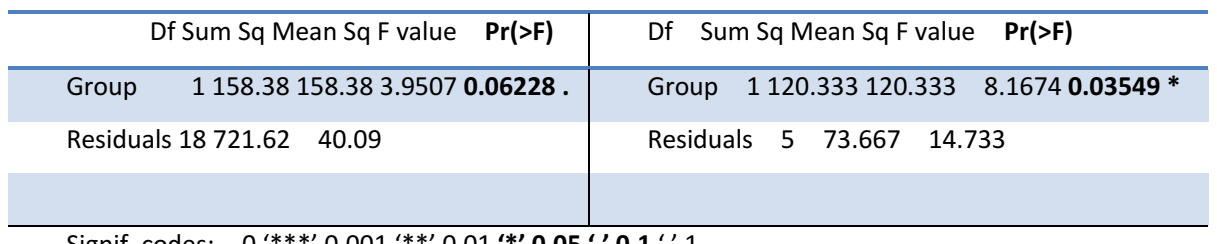

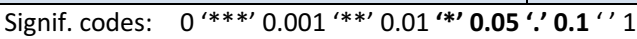

\footnotetext{
${ }^{7}$ http: / /www.r-project.org/
} 
The One-Way ANOVA analysis shows a significant rise in trust scores for the players in the CCIL study (where only the Group average of the trust values was evaluated - Group, $\mathrm{p}=0.06228$, left side Table 1) and in the NAIST study (where the individual trust levels where evaluated - Subject:Group, $\mathrm{p}=0.03549$, right side Table 1). For the CCIL study we were only interested in the general effect.

Additionally we evaluated both studies in a combined analysis (taking the study as a factor into account in the ANOVA analysis - labeled as "Experiment" in Table 2).

As the boxplot (left side of Figure 7) and the ANOVA results show the combination of the studies further improves the $p$-value $(p=0.02585)$ of the analysis - the nonsignificant factor "Experiment" allows us to combine the two studies in the first place.

Table 2. ANOVA result of the combined studies

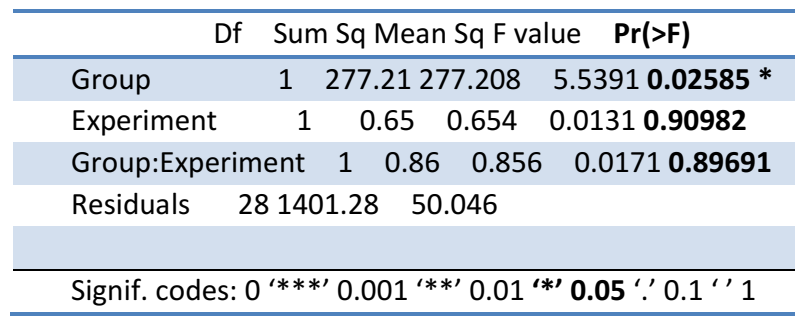

To verify that the increase in the trust level of the players of Kokochi didn't result from influences outside of the game experience we had a control group fill out the identical trust questionnaire during a two week period in the same time frame as the two studies took place. See the right side of Figure 7 for the boxplot. In the control group half of the participants resided inside of Japan (at the CCIL laboratory) and half were staying outside of Japan (in Bamberg, Germany) - all of them were nonJapanese. The age average was 34,8. The ANOVA results show that there was no significant effect measurable outside the game experience that may had caused the trust fostering effect of Kokochi $(\mathrm{p}=0.488$, see Table 3).

Table 3. ANOVA result of the control group

\begin{tabular}{|c|c|c|c|}
\hline & Df Sum Sc & Mean Sq F value & $\operatorname{Pr}(>\mathrm{F})$ \\
\hline Group & 64.0 & $64.00 \quad 0.5074$ & 0.488 \\
\hline Residuals & 141765.8 & 126.12 & \\
\hline \multicolumn{4}{|c|}{ Signif. codes: $0^{\prime * * * \prime} 0.001^{\prime * * \prime} 0.01^{\prime * \prime} 0.05{ }^{\prime \prime} 0.1^{\prime \prime} 1$} \\
\hline
\end{tabular}

\subsection{Discussion}

For the presented results three factors have to be taken into account. As it is not unusual in case studies in the computer science field both studies are biased towards male participants. Taken individually the number of participants in both studies was on the lower end of the spectrum to be able to generalize the presented findings. 
Taken together we think the number of participants is sufficient. The validity of the control group is limited as half of the participants did not reside in the same geographic region as the participants of the main studies.
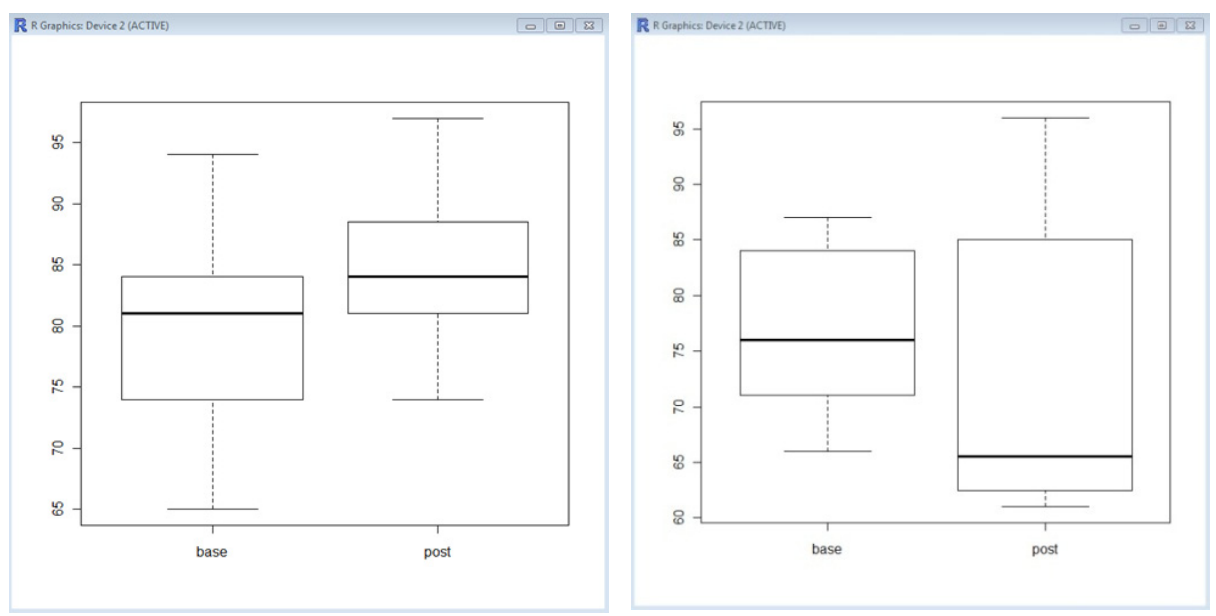

Fig. 7. Left: Trust values of the combined study (base $n=17$ and post $n=15$ ); Right: Trust values of the control group $(n=8)$

In addition to the trust questionnaire a general game-related questionnaire was filled out by the players after the game and also semi-structured interviews were conducted with the NAIST game participants. Also different kind of log data was recorded and reviewed with a custom-build viewer ${ }^{8}$.

One example can be seen in Figure 8 were we illustrate the temporal flow of the CCIL game with respect to the number of hugs, performed rituals and stated emotions. What the trend line indicates is that the number of emotions stated during the game period increases. We take that as an indicator that the game remained interesting for the players till the end and that it gave a sufficient motivation to the players to state their emotion with it. The same is true for the number of hugs. Looking at the raw numbers one can see that hugging was nearly as popular as stating emotions. This is even more surprising as hugging someone gives the players no immediate advantage in the game itself - also no misuse of the hugging feature was observed as discussed in section 3.1. In this context players agreed (11 out of 14) that getting hugged made them feel good but only four (with four neutral on this subject) agreed with the fact that hugging another player made them feel good. We suspect that the mood leveling of hugging is more subtle than the immediate feeling you have when getting hugged.

${ }^{8}$ http: / /81.20.134.106/moodGame_jp/map.html 


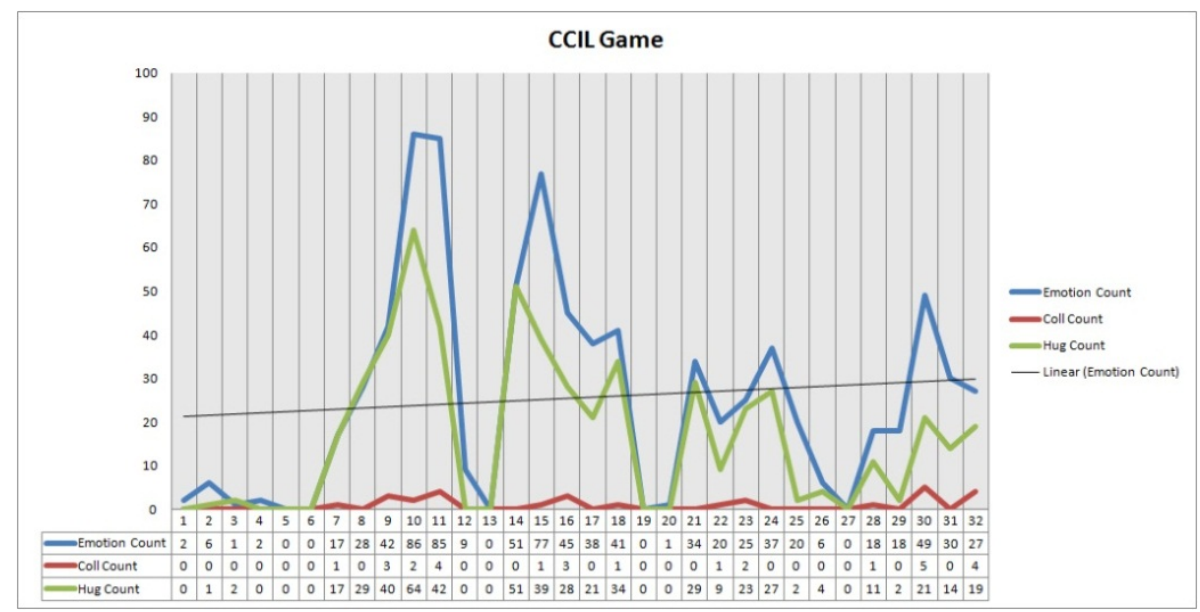

Fig. 8. Flow of the CCIL game: Number of hugs, performed rituals and number of stated emotions per day

\section{Conclusions and Outlook}

In this paper we presented the (location-based) game Kokochi that affects the trust level of its players in a positive way through the implementation of three unique game elements: emotion statements, hugging and rituals. As we have shown with the results of two case studies, playing the game results in a significant raise in the players interpersonal trust.

In our further research we will address the limitations of the presented studies, the number of participants, the bias towards male players and the construction of the control group. We also want to look into a more meaningful usage of the recorded GPS data within the game experience. Another interesting line of research could be to compare our presented emotion-based approach with more traditional forms of team building or sport activities in general.

With the help of more detailed studies we want to evaluate how each of the three used game elements contributed to the enhanced trust scores individually. Furthermore despite the methods we implemented in the current version of Kokochi cheating remains - especially in the emotion statement part - one of the biggest concerns with regard to a real-world usage of this kind of gameful trust building application. Here the answers of the post-game interviews give a first hint - namely to separate the emotion stating part from the rest of the game experience. That means that stating emotions themselves doesn't earn a player FPs. Players reported that they would nevertheless state their emotions in such a constellation. They especially liked the act that they could see the emotions statements of the other players. 
Acknowledgments. We want to thank Prof. Kato, Prof. Shibata and Prof. Nakamura from NAIST University for their help in the second case study. We also would like to thank Mariana Irigaray for the art work in Kokochi. This work was supported by the JSPS $^{9}$ scholarship program.

\section{References}

1. Anderson, I., Maitland, J., Sherwood, S., Barkhuus, L., Chalmers, M., Hall, M., Brown, B., Muller, H.: Shakra: Tracking and sharing daily activity levels with unaugmented mobile phones. Mob. Netw. Appl. 12(2-3), 185-199 (2007)

2. Berger, C.R., Calabrese, R.J.: Some Explorations in Initial Interaction and Beyond: Toward a Developmental Theory of Interpersonal Communication. Human Communication Research 1(2), 99-112 (1975)

3. Bell, M., Chalmers, M., Barkhuus, L., Hall, M., Sherwood, S., Tennent, P., Brown, B., Rowland, D., Benford, S., Capra, M., Hampshire, A.: Interweaving mobile games with everyday life. In: Grinter, R., Rodden, T., Aoki, P., Cutrell, E., Jeffries, R., Olson, G. (eds.) Proceedings of the SIGCHI Conference on Human Factors in Computing Systems (CHI 2006), pp. 417-426. ACM, New York (2006)

4. Bless, H., Fiedler, K.: Mood and the regulation of information processing and behavior. Affect in social thinking and behavior. In: Affect in Social Thinking and Behavior, pp. 65-84 (2006)

5. Blanchard, A.L., Markus, M.L.: The Experienced "Sense" of a Virtual Community: Characteristics and Processes. The DATA BASE for Advances in Information Systems 35(1), 65-79 (2004)

6. Castelfranchi, C., Falcone, R.: Principles of Trust for MAS: Cognitive Anatomy, Social Importance, and Quantification. In: Multi Agent Systems 1998, pp. $72-79$ (1998) IEEE 0-8186-8500-X

7. Church, K., Hoggan, E., Oliver, N.: A study of mobile mood awareness and communication through MobiMood. In: NordiCHI 2010, pp. 128-137 (2010) ACM 978-160558-934-3

8. Carrigy, T., Naliuka, K., Paterson, N., Haahr, M.: Design and evaluation of player experience of a location-based mobile game. In: Proceedings of the 6th Nordic Conference on Human-Computer Interaction: Extending Boundaries (NordiCHI 2010), pp. 92-101. ACM, New York (2010)

9. Dellarocas, C.: The Digitization of Word of Mouth - Promise and Challenges of Online Feedback Mechanisms. Management Science 49(10), 1407-1424 (2003)

10. Golbeck, J.A.: Computing and Applying Trust in Web-Based Social Networks. PhD thesis. Faculty of the Graduate School of the University of Maryland (2005)

11. Golbeck, J.A.: Trust on the World Wide Web: A Survey. Foundations and Trends in Web Science 1(2), 131-197 (2006)

12. George, M.J., Brief, P.A.: Feeling Good-Doing Good: A Conceptual Analysis of the Mood at Work-Organizational Spontaneity Relationship. Psychological Bulletin 112(2), 310-329 (1992)

13. Golembiewski, R.T., McConkie, M.: The Centrality of Interpersonal Trust in Group Processes. In: Cooper, C.L. (ed.) Theories of Group Processes, ch. 7, pp. 131-185. Wiley (1975)

\footnotetext{
${ }^{9}$ http: //www.jsps.go.jp/english/e-fellow/
} 
14. Goodchild, M.F.: Citizens as Voluntary Sensors: Spatial Data Infrastructure in the World of Web 2.0. International Journal of Spatial Data Infrastructures Research 2, 24-32 (2007) ISSN: 17250463

15. Jones, K.: Trust as an Affective Attitude. Ethics 107(1), S.4-S.25 (1996)

16. Johnson, W.L.: Serious Use of a Serious Game for Language Learning. Int. J. Artif. Intell. Ed. 20(2), 175-195 (2010)

17. Jegers, K.: Pervasive game flow: understanding player enjoyment in pervasive gaming. Comput. Entertain. 5(1), Article 9 (January 2007)

18. Jarvenpaa, S.L., Leidner, D.E.: Communication and Trust in Global Virtual Teams. Organization Science 10(6), 791-815 (1999)

19. Kramer, R.M.: Trust and Distrust in Organizations: Emerging Perspectives, Enduring Questions. Annu. Rev. Psychol. 50, 569-598 (1999)

20. Robert Jr., L., Denis, A., Hung, Y.-T.: Individual Swift Trust and Knowledge-Based Trust in Face-to-Face and Virtual Team Members. J. Manage. Inf. Syst. 26(2), 241-279 (2009)

21. Lount, R.B.: The impact of positive mood on trust in interpersonal and intergroup interactions. Journal of Personality and Social Psychology 98(3), 420-433 (2010)

22. Marsh, S.P.: Formalising Trust as a Computational Concept. PhD thesis. University of Stirling, Stirling. Department of Computing Science and Mathematics (1994)

23. Matyas, S., Matyas, C., Mitarai, H., Kamata, M., Kiefer, P., Schlieder, C.: Designing Location-based Mobile Games - The CityExplorer Case Study. In: de Souza e Silva, A., Sutko, D.M. (eds.) Digital Cityscapes: Merging Digital and Urban Playspaces, vol. 6, pp. 187-203. Peter Lang Publishers, NY (2009) ISBN 978-1-4331-0532-6

24. Mayer, J.D., Gaschke, Y.N., Braverman, D.L., Evans, T.W.: Mood-Congruent Judgment Is a General Effect. Journal of Personality and Social Psychology 63(1), 119-132 (1992)

25. Mueller, F., Stevens, G., Thorogood, A., O’Brien, S., Wulf, V.: Sports over a Distance. Personal Ubiquitous Comput. 11(8), 633-645 (2007)

26. Robinson, J.P., Wrightsman, L.S., Andrews, F.M.: Measures of personality and social psychological attitudes: Academic Pr. Inc. (Measures of Social Psychological Attitudes, 1) (1991)

27. Bernhaupt, R., Boldt, A., Mirlacher, T., Wilfinger, D., Tscheligi, M.: Using emotion in games: emotional flowers. In: Proceedings of the International Conference on Advances in Computer Entertainment Technology (ACE 2007), pp. 41-48. ACM, New York (2007)

28. Russell, J.A.: A circumplex model of affect. Journal of Personality and Social Psychology 39(6), 1161-1178 (1980)

29. Virtanen, T., Malinen, S.: Supporting the Sense of Locality with Online Communities. In: MindTrek 2008, pp. 145-149 (2008) ACM 978-1-60558-197-2/08/10

30. von Ahn, L., Dabbish, L.: Designing games with a purpose. Commun. ACM 51(8), 58-67 (2008)

31. Yamagishi, M.: Trust and commitment in the United States and Japan. Motivation and Emotion 18(2), 129-166 (1994)

32. Yamagishi, T., Cook, K.S., Watabe, M.: Uncertainty, Trust, and Commitment Formation in the United States and Japan. Am. J. Sociol. 104(1), 165-194 (1998) 